\title{
openheart Variabilities in the mortality-related resource utilisation for congenital heart disease
}

\author{
David A Danford, Quentin Karels, Shelby Kutty
}

To cite: Danford DA, Karels $Q$, Kutty $S$. Variabilities in the mortality-related resource utilisation for congenital heart disease. Open Heart 2016;3:e000415. doi:10.1136/openhrt-2016000415

- Additional material is available. To view please visit the journal online (http://dx. doi.org/10.1136/openhrt2016-000415)

Received 20 January 2016 Revised 21 March 2016 Accepted 29 March 2016

\section{CrossMark}

University of Nebraska Medical Center College of Medicine, Children's Hospital and Medical Center, Omaha, Nebraska, USA

Correspondence to Dr Shelby Kutty; skutty@ unmc.edu

\section{ABSTRACT}

Objective: Our objective was to characterise the divergence of effort from outcome in congenital heart disease (CHD) care by measuring mortality-related resource utilisation fraction (MRRUF) for various CHD lesions across institutions of differing volumes.

Methods: Study design was observational analysis of an administrative database, the Pediatric Health Information System (PHIS). The setting was inpatient; 2004-2013. Patients were $\leq 21$ years old with atrial septal defect (ASD), ventricular septal defect (VSD), tetralogy of Fallot (TOF), hypoplastic left heart syndrome (HLHS) or other single ventricle (SV). There were no interventions but diagnosis, institution (and volume), age, length of hospitalisation, billed charges and deaths were recorded. The main outcome measure was MRRUF, the ratio of investments during hospitalisations ending in fatality to investments during all hospitalisations.

Results: There were 50939 admissions, 1711 deaths, 703383 inpatient days, and $\$ 10182000000$ billed charges. MRRUF varied widely by diagnosis: highest in HLHS (21\%), but present in ASD (2\%) and VSD (4\%). Highest among the very young, MRRUF also increased in HLHS and SV during adolescence. MRRUF increased with hospitalisation duration. MRRUF had no relation to institutional volume, and was static over the decade studied.

Conclusions: Even in the modern era we invest heavily in inpatient CHD care that does not produce the desired outcome. Although its magnitude varies by lesion and age, MRRUF is not limited to complex disease in the very young. MRRUF is not decreasing, and is not isolated to high or low volume institutions.

\section{INTRODUCTION}

Surgical and medical management of congenital heart disease (CHD) has made great progress in the past 50 years. ${ }^{1-3}$ Advances in CHD care have made survival to adulthood commonplace, ${ }^{45}$ and publicity surrounding these successes have altered public perceptions and expectations. ${ }^{6-11}$ Dramatic successes with surgical and catheter-mediated management of previously lethal cardiac defects are worthy of acclaim, but have had

\section{KEY QUESTIONS}

What is already known about this subject?

- The mortality-related resource utilisation fraction is high in congenital heart disease. It shows no sign of falling with the passage of time, even as mortality rates gradually improve.

What does this study add?

- While mortality-related resource utilisation is greater in the care of complex congenital heart disease, there is a high level of such investment in the care of simpler forms of disease. It is consistent across all cardiac programmes, irrespective of whether these represent high or low volume. It is high in the young, and in patients with complex disease approaching adulthood.

How might this impact on clinical practice?

- Clinical strategies to optimise use of resources may result in lower mortality-related resource utilisation and greater efficiencies in congenital heart disease care.

two key consequences: (1) have encouraged an aggressive investment of resources from the medical community to replicate these astounding successes case after case, and (2) fostered high expectations from the lay community. Despite this progress, much of inpatient CHD care remains intensive, unpredictable, and occasionally unsuccessful. Indeed, when we measured the mortality-related resource utilisation fraction (MRRUF) in Children's Hospitals in the USA, we found $16 \%$ of hospital days and $21 \%$ of billed charges (BC) for hypoplastic left heart syndrome (HLHS) inpatient care occur during hospitalisations of patients who do not survive. ${ }^{12}$ It is not known whether these values represent an ideal MRRUF, in which resources are neither expended in futility nor withheld when they might have fostered a favourable outcome. Further context is required. Therefore, it is the purpose of this investigation to answer: (1) What is the MRRUF for other less severe 
forms of CHD? (2) Are there institutional tendencies toward higher or lower MRRUF in the USA and if so, are they related to the size of the CHD programme? (3) Is MRRUF related to the age of the patient? (4) Is MRRUF increasing, decreasing or static over time?

\section{METHODS}

The Pediatric Health Information System (PHIS) database representing 47 children's hospitals was queried for patients $\leq 21$ years old with atrial septal defect (ASD), ventricular septal defect (VSD), tetralogy of Fallot (TOF), single ventricle (SV) and HLHS admissions receiving inpatient care during 2004-2013. These represent International Classification of Diseases Ninth Revision (ICD-9) codes 745.2, 745.3, 745.4, 745.5 and 746.7. All patients were included regardless of whether or not a surgical procedure was performed. PHIS (managed by Children's Hospital Association in Overland Park, Kansas, USA) is an administrative database containing comprehensive inpatient, observation, ambulatory surgery and emergency department data from 47 not-for-profit children's hospitals belonging to an alliance of free-standing paediatric hospitals. Data are identified, and undergo quality and validity checks before inclusion in the PHIS database. Hospital charge data is submitted to a third party vendor who codes the data using a standard proprietary methodology to ensure comparability across hospitals; the data is then loaded on to the PHIS database. Resource use information collected for the present study included diagnosis using ICD-9 coding, admit age, number of cases, mortality, charges and average length of stay (LOS). Hospital characteristics, including centre and location, were also collected.

Institution, patient age at hospital admission, inpatient deaths, BC and LOS were recorded for further analysis. Measures of central tendency for the data were presented as mean, median and IQR. The mortality-related resource utilisation fraction (MRRUF) was calculated based on BC and on LOS:

1. LOS-based MRRUF=LOS for hospitalisations resulting in fatality/Total LOS

2. BC-based MRRUF=BC for hospitalisations resulting in fatality/Total BC

MRRUF was calculated for the total study population according to CHD lesion, age of patient, year of admission and institutional volume in the LOS and BC domains.

Volume of admissions for ASD, VSD, TOF, SV and HLHS and lesion-specific mortality rates were calculated for each institution. Comparisons of non-normally distributed continuous variables between groups were made using the Mann-Whitney $\mathrm{U}$ test. Least square regression analysis was used to assess for potential associations between continuous variables. Level of significance for all statistical tests was $\mathrm{p}<0.05$ except for pairwise comparisons of MRRUF among the 5 cardiac lesions, in which the Bonferonni adjustment produced a level of significance $p<0.005$. Statistical analysis was performed with commercially available computer software (Minitab 16.0, Minitab Inc, State College, Pennsylvania, USA).

\section{RESULTS}

In all, 50939 admissions were identified from 43 institutions (mean 1184.6 \pm 643.7 per institution), which accounted for total LOS of 703783 inpatient days and $\$ 10182000000$ in BC. There were 1711 inpatient deaths $(3.36 \%)$. Lesion by lesion, there were substantial variations in LOS, BC, MRRUF and institutional volumes (see table 1).

For each lesion, LOS, BC and MRRUF were significantly greater for hospitalisations ending in death than they were for non-fatal hospitalisations $(p<0.001)$. MRRUF varied widely by cardiac lesion, with close to $20 \%$ found for HLHS, $8-10 \%$ for TOF and SV and about 2\% MRRUF for secundum ASD (figure 1). Differences in MRRUF among diagnosis groups were all associated with $\mathrm{p}<0.005$ (the criterion for statistical significance after Bonferonni adjustment for multiple comparisons) except for the comparison between SV and TOF, in which $p>0.005$. MRRUF calculated on the basis of BC was generally somewhat higher than when it was based on hospital days. When the five lesions were considered together (figure 2), MRRUF did not vary by institutional volume $(\mathrm{p}=0.277$ charge based; $\mathrm{p}=0.095$ LOS based). When each individual CHD lesion was analysed by institutional volume, no significant association of MRRUF with institutional volume was identified.

Considering the combined series of all five lesions, mortality rates and MRRUF were highest $(p<0.001$ for age $<1$ year vs all other) in the youngest patients (figure 3). For more complex diseases like HLHS and other single ventricles, there was a rise in MRRUF and mortality in late childhood and adolescence $(p<0.001$ for age $>13$ years vs age 1-13 years). With greater length of hospital stay, there was higher MRRUF (figure 4). However, even at the longest duration of stay, only about $30 \%$ of BC were accrued for care that failed to result in survival at hospital dismissal. When the entire population is considered together, there is no association ( $\mathrm{p}=0.427$ charge based; $\mathrm{p}=0.286$ LOS based) between calendar year and MRRUF (figure 5). Similarly, for each lesion considered individually, MRRUF cannot be demonstrated to be increasing or decreasing during the decade 2004-2013.

Mortality rates fell significantly $(p<0.001)$ during the years included in this analysis (figure 6, upper panel). Concurrently, BC per case in this period have increased both for survivors and for non-survivors (figure 6, lower panel). Although inflation is expected to cause unadjusted charges to rise over a 10 -year period, it is notable that the rate of rise in $\mathrm{BC}$ for non-survivors is 
Table 1 Lesion-specific findings

\begin{tabular}{|c|c|c|c|c|c|}
\hline $\begin{array}{l}\text { Lesion } \\
\mathrm{N} \text { (admissions) } \\
\mathrm{N} \text { (deaths) }\end{array}$ & $\begin{array}{l}\text { ASD } \\
9926 \\
28\end{array}$ & $\begin{array}{l}\text { VSD } \\
14200 \\
102\end{array}$ & $\begin{array}{l}\text { TOF } \\
12891 \\
344\end{array}$ & $\begin{array}{l}\text { SV } \\
2800 \\
92\end{array}$ & $\begin{array}{l}\text { HLHS } \\
11122 \\
1145\end{array}$ \\
\hline \multicolumn{6}{|l|}{ Age (years) } \\
\hline Mean & 4.76 & 1.23 & 1.14 & 2.23 & 1.13 \\
\hline Median & 3 & 0 & 0 & 0 & 0 \\
\hline $\mathrm{IQ}$ range & $1-6$ & $0-1$ & $0-0$ & $0-3$ & $0-2$ \\
\hline \multicolumn{6}{|c|}{ LOS-all cases (days) } \\
\hline Mean & 4.70 & 8.82 & 15.18 & 16.22 & 24.91 \\
\hline Median & 3 & 5 & 7 & 9 & 12 \\
\hline$I Q$ range & $2-4$ & $3-8$ & $5-14$ & $5-16$ & $6-29$ \\
\hline \multicolumn{6}{|c|}{ LOS-fatalities (days) } \\
\hline Mean & 43.7 & 41.83 & 47.13 & 46.09 & 38.62 \\
\hline Median & 22 & 18 & 21 & 21 & 17 \\
\hline$I Q$ range & $2-75$ & $8-56$ & $7-57$ & $8-71$ & $6-48$ \\
\hline \multicolumn{6}{|c|}{ MRRUF (LOS domain) } \\
\hline Mean & 0.028 & 0.035 & 0.077 & 0.096 & 0.146 \\
\hline Median & 0 & 0.031 & 0.062 & 0.062 & 0.145 \\
\hline$I Q$ range & $0-0.022$ & $0.002-0.056$ & $0.040-0.10$ & $0.004-0.126$ & $0.090-0.200$ \\
\hline \multicolumn{6}{|c|}{ BC—all cases (dollars) } \\
\hline Mean & 82606 & 127626 & 231216 & 228423 & 353245 \\
\hline Median & 59429 & 87414 & 120572 & 129380 & 174624 \\
\hline$I Q$ range & $41524-87812$ & 58 183-131413 & $73762-212642$ & 77 287-226 728 & $85766-391941$ \\
\hline \multicolumn{6}{|c|}{ BC—fatalities (dollars) } \\
\hline Mean & 637224 & 725221 & 882392 & 752416 & 722445 \\
\hline Median & 288147 & 339421 & 509875 & 465827 & 409312 \\
\hline$I Q$ range & $120561-839947$ & 155 370-982 239 & $188898-1078138$ & $147068-1028334$ & 139 933-964 157 \\
\hline \multicolumn{6}{|c|}{ MRRUF (BC domain) } \\
\hline Mean & 0.029 & 0.041 & 0.096 & 0.112 & 0.20 \\
\hline Median & 0 & 0.032 & 0.083 & 0.091 & 0.206 \\
\hline$I Q$ range & $0-0.018$ & $0.002-0.066$ & $0.057-0.117$ & $0.008-0.170$ & $0.140-0.261$ \\
\hline \multicolumn{6}{|c|}{ Cases/institution/10 years } \\
\hline Mean & 230.8 & 330.2 & 299.8 & 65.1 & 258.7 \\
\hline Median & 199 & 325 & 294 & 56 & 253 \\
\hline $\mathrm{IQ}$ range & $136-277$ & $250-423$ & $212-356$ & $29-84$ & $136-354$ \\
\hline
\end{tabular}

ASD, atrial septal defect; BC, billed charges in dollars; HLHS, hypoplastic left heart syndrome; LOS, length of stay; MRRUF, mortality-related resource utilisation fraction; N, number; SV, single ventricle; TOF, tetralogy of Fallot; VSD, ventricular septal defect;

All LOS, BC, MRRUF, and institutional volume data are expressed as mean, median, IQR.

diverging from that for survivors $(\mathrm{p}<0.001)$. Online supplementary figures S1 and S2 show the early trends in the lesion-wise MRRUF in the BC domain, and trends in MRRUF for each lesion by institutional volume.

\section{DISCUSSION}

Our data demonstrate that current practices result in measurable MRRUF for all CHD lesions analysed so far. Even for secundum ASD, acknowledged by many to be a condition that is very responsive to modern management, ${ }^{13}$ about $2 \%$ of the hospital days and charges are accrued among patients who do not survive their hospital stay. As expected, the MRRUF rises with the perceived complexity of the cardiac lesion: $\mathrm{ASD}<\mathrm{VSD}<\mathrm{TOF}$ and $\mathrm{SV}<\mathrm{HLHS}$. It is notable that MRRUF in SV is substantially less than that in HLHS, even though both lesions are managed with a univentricular surgical palliative strategy. The data available do not directly indicate the reason for this, but we speculate that because many $\mathrm{SV}$ are of left ventricular morphology and some do not require aortic reconstruction, on average these have fewer and less threatening clinical vulnerabilities than HLHS. ${ }^{14}$ SV MRRUF is actually much closer to that observed in TOF. This highlights the clinical complexities of TOF that can contribute to lengthy, expensive and unsuccessful inpatient care which evidently can rival SV. The association of TOF with chromosomal anomalies and VACTERL ${ }^{15} 16$ imply comorbidities which may have contributed to the complexity of care and the disappointing outcomes. To a lesser extent, VSD carries many similar associations ${ }^{17}$ and comorbidities. This could account for the observed MRRUF of roughly $4 \%$ despite the reputation VSD enjoys as a straightforward form of CHD for which treatment is well established and successful. ${ }^{18}$

Regardless of the lesion, there is much variation in MRRUF among institutions. This raises a natural 
MRRUF (Billed Charges) by Lesion
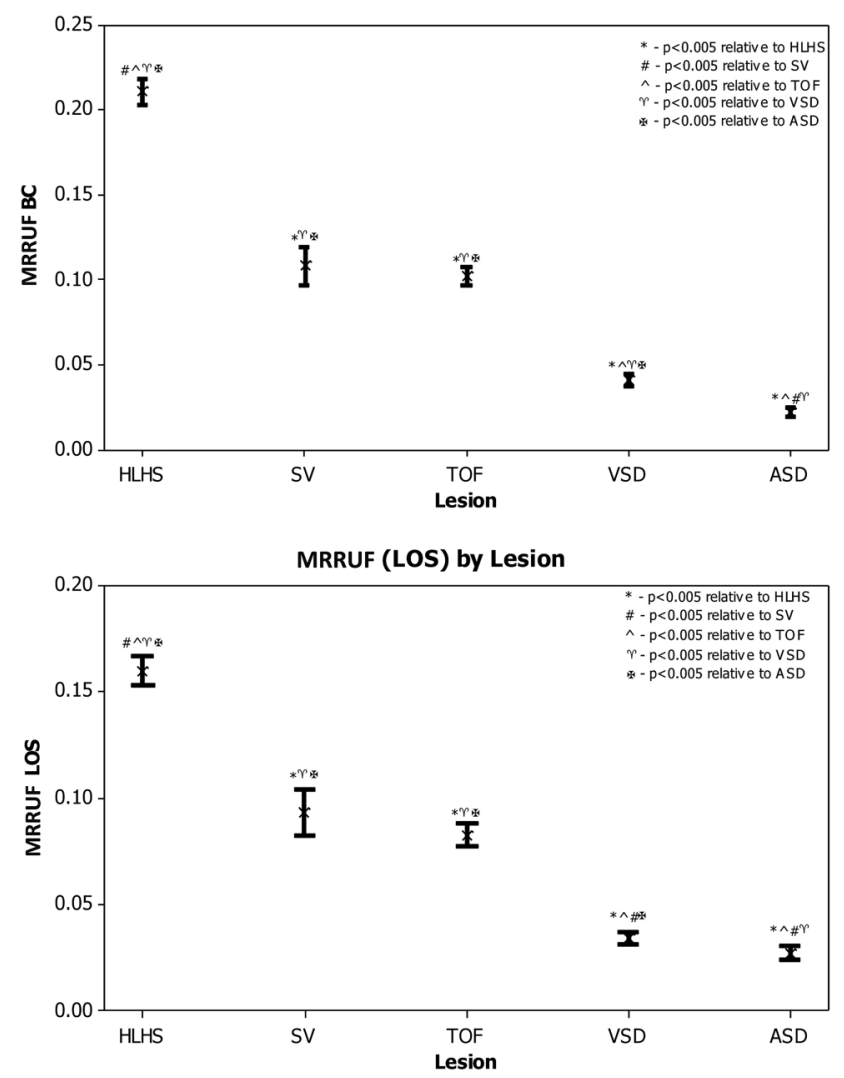

Figure 1 Variation of MRRUF by lesion. MRRUF is highest among complex lesions, but even simpler lesions have measurable MRRUF. ASD, secundum atrial septal defect; BC, billed charges; HLHS, hypoplastic left heart syndrome; LOS, length of stay; MRRUF, mortality-related resource utilisation fraction; SV, single ventricle; TOF, -tetralogy of Fallot; VSD, ventricular septal defect.

question of whether there could be institutional factors at work such as institutional volume. While theoretical arguments could be advanced that high or low volume centres may bring greater efficiencies to CHD care resulting in lower MRRUF, ${ }^{19}$ our results show no such institutional volume related trends.

High MRRUF in CHD generally concentrates among the very young, where mortality risk and intensity of inpatient care is highest. For lesions like HLHS and SV, which are managed with palliative rather than definitive surgeries, MRRUF rises as adulthood approaches. This highlights increasing risk of mortality at this age, despite heavy utilisation of resources. Although outside the scope of this investigation, we speculate that beyond the age of 21 years, perhaps towards middle age, a similar phenomenon could be observed in TOF for which intracardiac repair is not entirely definitive. ${ }^{20}$

The optimist would propose that as care for CHD continues to improve, it becomes more successful and more efficient, and MRRUF should fall. The pessimist would point to recent general trends within medicine to allocate greater resources to more desperate clinical circumstances, ${ }^{21-23}$ and expect that MRRUF must be rising.
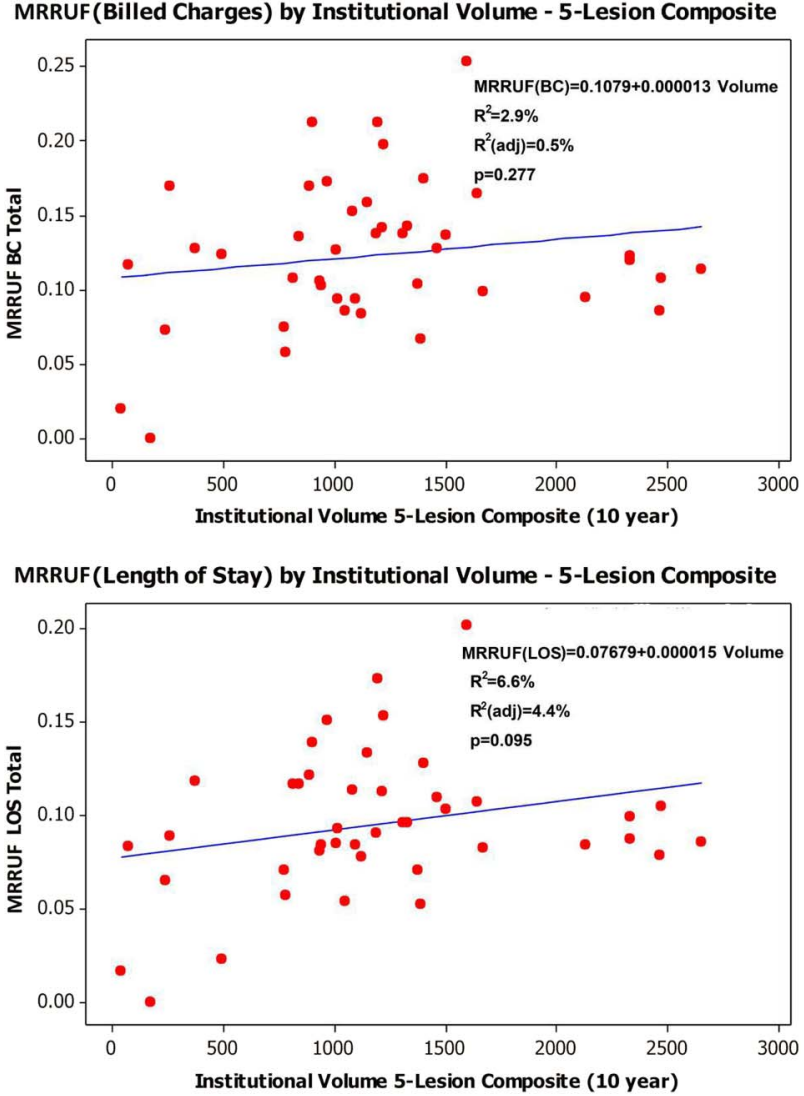

Figure 2 Relation between institutional volume and MRRUF. No significant relation is identified between institutional volume and mortality-related resource utilisation fraction, analysed by billed charges or length of hospital stay. BC, billed charges; LOS, length of stay; MRRUF, mortality-related resource utilisation fraction.

Our findings do not support either view, and confirm that for the lesions investigated, MRRUF is constant from 2004 to 2013.

Mortality Rate, MRRUF by Age Category - All Lesions

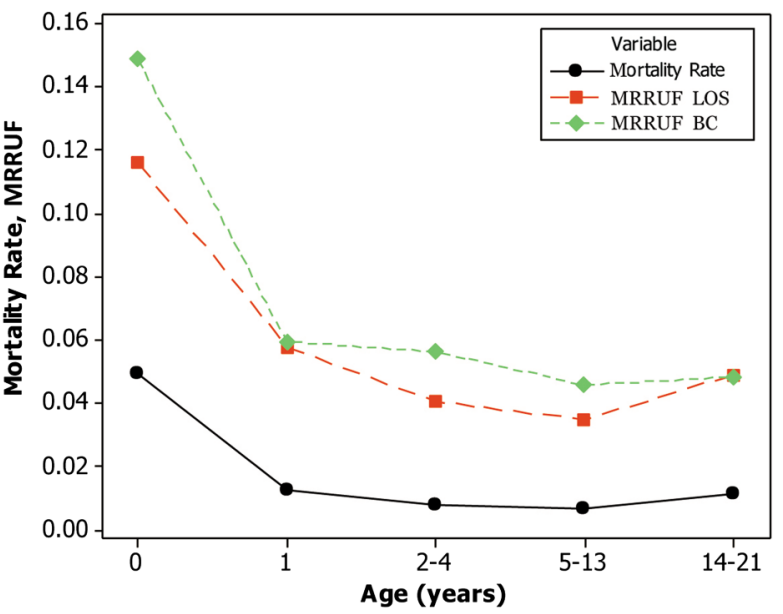

Figure 3 MRRUF and mortality rate by age in the entire population. MRRUF and mortality rate by age in the entire population demonstrates these are highest in infancy. BC, billed charges; LOS, length of stay; MRRUF, mortality-related resource utilisation fraction. 


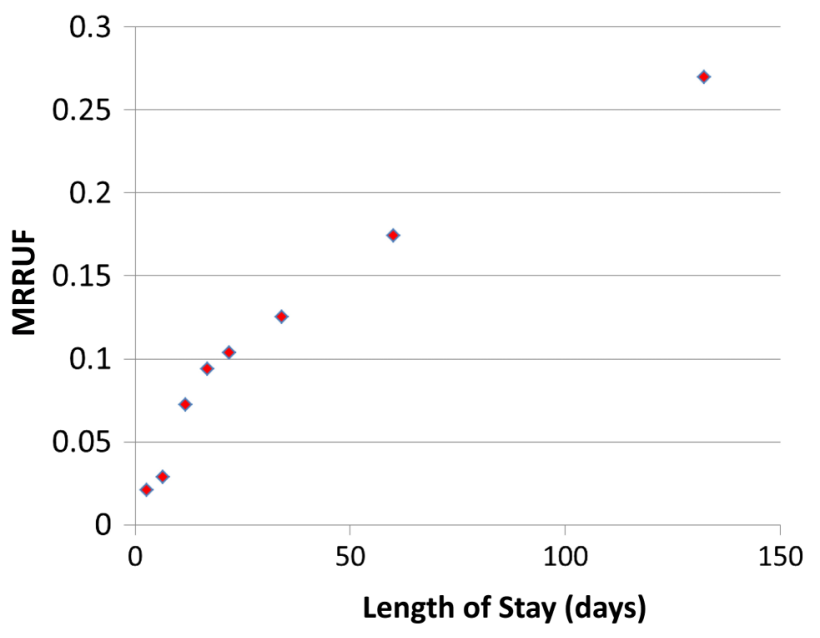

Figure 4 Relationship of billed charges-based MRRUF and hospital stay. For the entire group of five lesions, there was a striking increase in billed charges-based MRRUF with longer hospital stay. MRRUF, mortality-related resource utilisation fraction.

High MRRUF can imply many things, positive and negative. Among the positive, it implies a willingness to take on difficult clinical challenges, even those not

A Yearly Trend in MRRUF - All Lesions (Billed Charges Domain)

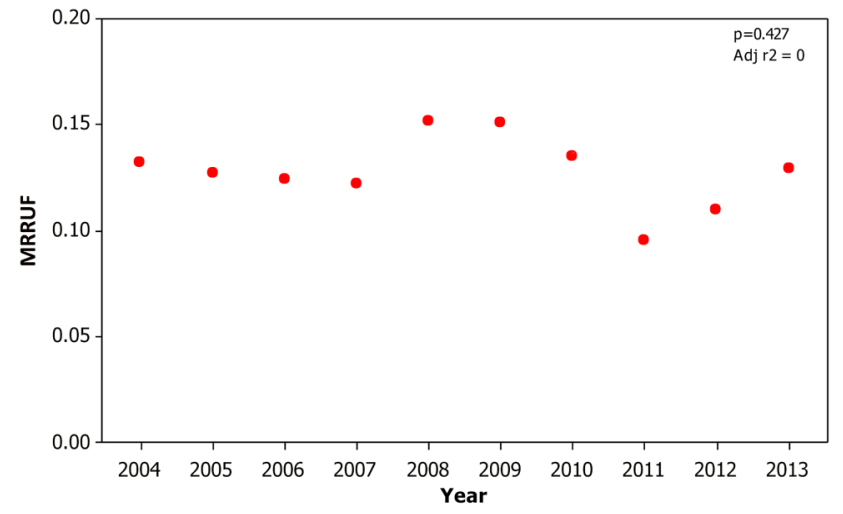

B Yearly Trend in MRRUF - All Lesions (Length of Stay Domain)

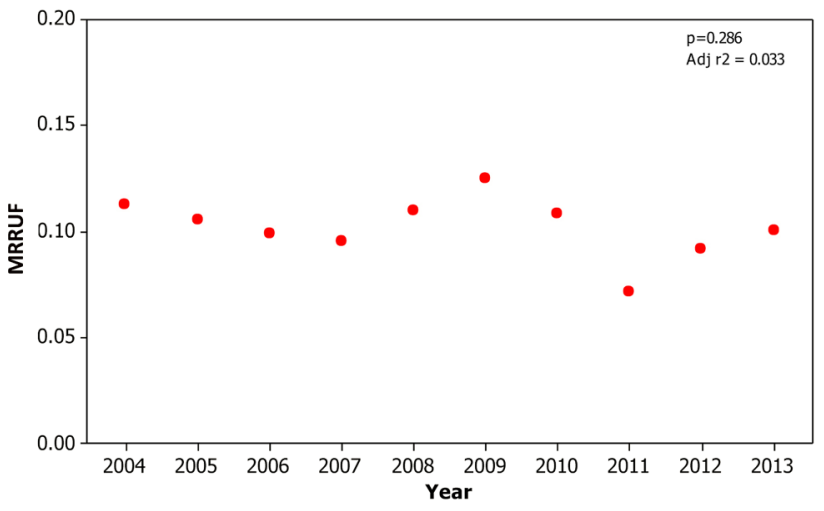

Figure 5 Year-wise trends in MRRUF. For the entire study population, whether analysed by billed charges $(A)$ or length of hospitalisation (B), no trend is found when mortality-related resource utilisation fraction is examined year by year. MRRUF, mortality-related resource utilisation fraction.
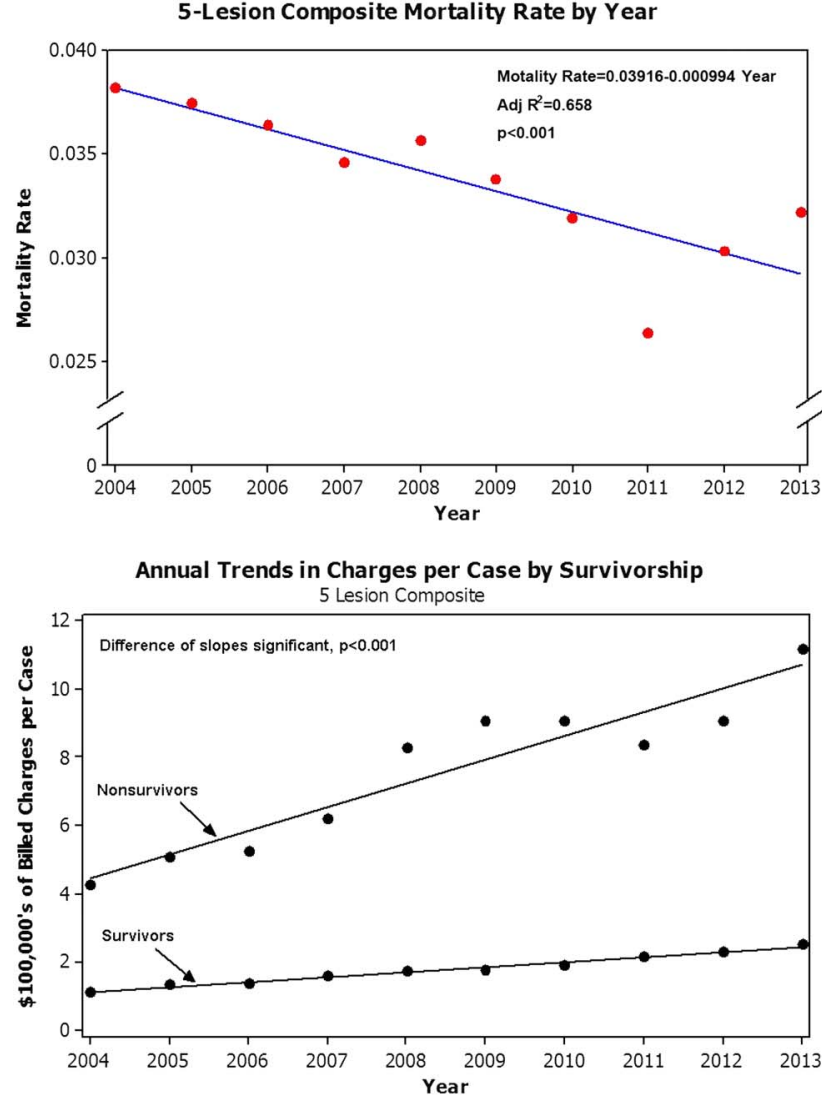

Figure 6 Composite mortality rate by year for five lesions (upper panel) and annual trends in charges per case by survivorship (lower panel).

guaranteed to produce a survivor, and persevere as an advocate for such patients who might survive if we invest enough resources in their care. The negative implication of high MRRUF is that of clinical management run amok, crossing the line from a good investment with a real possibility of producing success to becoming a poor investment that merely delays the proof of failure due to mortality. It is beyond the scope of this work to what level of MRRUF indicates that the line is being routinely crossed.

Regardless of whether it represents positive or negative clinical behaviour, a strong case can be made that high MRRUF takes a toll in at least three ways: (1) Stewardship of resources: By definition, MRRUF costs money and resources for a cause that ultimately fails. We regret this inefficiency, of course and wish we could have put our resources toward a successful purpose; (2) Impact on patients' families: Patients, their families and workers caring for them must prospectively arrive at a shared understanding that a small portion of inpatients die with their CHD, and that high levels of resource utilisation does not always prevent this; (3) Effects on healthcare workers:Although this has not been formally studied, it seems highly likely that workers in a high MRRUF environment would be prone to experience 'moral distress'. In recent years, the concept of moral 
distress has rightly received a great deal of attention. ${ }^{24-28}$ It occurs among caregivers who, without meaningful participation in the decisions to proceed, must execute the orders for aggressive, perhaps uncomfortable, expensive care for patients in whom they believe such care to be futile. As others have previously published, the consequences of moral distress are potentially devastating to the individual caregiver, but damage to the programme should not be underestimated.$^{25}$ Furthermore, with each difficult case, measures must be taken to enfranchise all team members in decision-making to minimise moral distress.

\section{Limitations}

Analysis of an administrative database to recognise MRRUF, measure it, and characterise the conditions in which it is highest is, therefore, descriptive rather than prescriptive. More clinical detail than can be acquired in this study will be required to develop clinical strategies to optimise use of resources in the care of children with CHD. The investigators acknowledge that this work depends on the accuracy of coding and data entry, factors over which they had no direct control. We also recognise that $\mathrm{BC}$ and reimbursement are not easily convertible to actual costs. ${ }^{29}$ However, the MRRUF, normalised as it is to total investment, does not suffer from the inaccuracies of conversion from BC to actual costs, nor is it subject to distortion from inflation. Nevertheless, as MRRUF is not a cost measure per se, it cannot be incorporated into a classic cost-benefit analysis. The study is limited to selected common CHD lesions, and cannot be extrapolated to other forms of CHD.

It is expected that hospitalisations that involve cardiac surgery would have higher mortality rates, and more expensive care than non-surgical hospital stays. This investigation is limited because it was not designed to test this hypothesis. The nature and extent of the surgeries for CHD are heterogeneous, even when the surgeries might share the same name in a database. Moreover, the circumstances under which they take place are diverse, and are not anticipated to be understood in detail from an administrative database. With the concern that confounding and easily misinterpreted information might be introduced, no attempt was made in this investigation to analyse surgery as a promoter of MRRUF. To better understand the influence of various cardiac surgeries on MRRUF, a prospective study designed to gather appropriate clinical detail would be warranted.

\section{CONCLUSIONS}

The limitations of this study do not diminish the importance of the main conclusions drawn: (1) there is substantial investment of inpatient resources in fatal outcomes in CHD and while it is greater in the care of complex disease, there is also a high level of such investment in the care of simpler forms of CHD; (2) there is no consistent relationship between MRRUF and institutional volume; (3) MRRUF is high in the young and in patients with complex disease approaching adulthood; (4) MRRUF is neither increasing nor decreasing over the recent decade. We must acknowledge there will always be MRRUF, and that efforts to reduce MRRUF to zero would be misguided failures. However, we must ensure that the care MRRUF represents is delivered with transparency to the family, by caregivers without moral distress and orchestrated by physician leaders ever watchful that they are not crossing the line to futility.

Acknowledgements The authors acknowledge the assistance of Ameya Kutty and Ming Zhang, MD PhD. All authors have no conflicts of interest to disclose the data.

Contributors QK performed the data collection. DAD and SK designed the study, and performed the analysis. DAD and SK drafted the manuscript. All authors read and approved the final manuscript.

Competing interests None declared.

Patient consent Obtained.

Provenance and peer review Not commissioned; externally peer reviewed.

Data sharing statement No additional data are available.

Open Access This is an Open Access article distributed in accordance with the Creative Commons Attribution Non Commercial (CC BY-NC 4.0) license, which permits others to distribute, remix, adapt, build upon this work noncommercially, and license their derivative works on different terms, provided the original work is properly cited and the use is non-commercial. See: http:// creativecommons.org/licenses/by-nc/4.0/

\section{REFERENCES}

1. Williams WG. Surgical outcomes in congenital heart disease: expectations and realities. Eur J Cardiothorac Surg 2005;27:937-44.

2. Khairy $P$, lonescu-Ittu $R$, Mackie AS, et al. Changing mortality in congenital heart disease. J Am Coll Cardiol 2010;56:1149-57.

3. Nieminen HP, Jokinen EV, Sairanen HI. Late results of pediatric cardiac surgery in Finland: a population-based study with 96\% follow-up. Circulation 2001;104:570-5.

4. Warnes CA, Liberthson R, Danielson GK, et al. Task force 1: the changing profile of congenital heart disease in adult life. J Am Coll Cardiol 2001;37:1170-5.

5. Knowles RL, Bull C, Wren C, et al. Modelling survival and mortality risk to 15 years of age for a national cohort of children with serious congenital heart defects diagnosed in infancy. PLOS ONE 2014;9: e106806.

6. Foreman T. Ethics, rhetoric, and expectations: responsibilities and obligations of health care systems. J Bioeth Inq 2014;11:295-9.

7. Cicero K. 10 best children's hospitals. http://www.parents.com/ health/doctors/best-childrens-hospitals (accessed 4 Feb 2013).

8. Leonard K. The honor roll of best children's hospitals 2014-2015. http://health.usnews.com/health-news/best-childrens-hospitals/ slideshow/the-honor-roll-of-best-childrens-hospitals-2014-15 (accessed 10 Jun 2014).

9. Reid GJ, Webb GD, Barzel M, et al. Estimates of life expectancy by adolescents and young adults with congenital heart disease. J Am Coll Cardiol 2006;48:349-55.

10. Shearer K, Rempel GR, Norris CM, et al. "It's no big deal": adolescents with congenital heart disease. J Pediatr Nurs 2013;28:28-36.

11. Weinstein ND, Klein WM. Unrealistic optimism: present and future. $J$ Soc Clin Psychol 1996;15:1-8.

12. Danford DA, Karels Q, Kulkarni A, et al. Mortality-related resource utilization in the inpatient care of hypoplastic left heart syndrome. Orphanet J Rare Dis 2015;10:137.

13. Geva T, Martins JD, Wald RM. Atrial septal defects. Lancet 2014;383:1921-32.

14. lyengar AJ, Winlaw DS, Galati JC, et al. Trends in Fontan surgery and risk factors for early adverse outcomes after Fontan surgery: the Australia and New Zealand Fontan Registry experience. J Thorac Cardiovasc Surg 2014;148:566-75. 
15. Piran S, Bassett AS, Grewal J, et al. Patterns of cardiac and extracardiac anomalies in adults with tetralogy of Fallot. Am Heart $J$ 2011;161:131-7.

16. Garne E, Nielsen G, Hansen OK, et al. Tetralogy of Fallot. A population-based study of epidemiology, associated malformations and survival in western Denmark 1984-1992. Scand Cardiovasc $J$ 1999;33:45-8.

17. Cunningham BK, Hadley DW, Hannoush $\mathrm{H}$, et al. Analysis of cardiac anomalies in VACTERL association. Birth Defects Res Part A Clin Mol Teratol 2013:97:792-7.

18. Scully BB, Morales DL, Zafar F, et al. Current expectations for surgical repair of isolated ventricular septal defects. Ann Thorac Surg 2010;89:544-51.

19. Checchia PA, McCollegan J, Daher N, et al. The effect of surgical case volume on outcome after the Norwood procedure. J Thorac Cardiovasc Surg 2005;129:754-9.

20. Kim H, Sung SC, Kim SH, et al. Early and late outcomes of total repair of tetralogy of Fallot: risk factors for late right ventricular dilatation. Interact Cardiovasc Thorac Surg 2013;17:956-62.

21. Zilberberg MD, Shorr AF. Economics at the end of life: hospital and ICU perspectives. Semin Respir Crit Care Med 2012;33:362-9.

22. Dionne JM, d'Agincourt-Canning L. Sustaining life or prolonging dying? Appropriate choice of conservative care for children in end-stage renal disease: an ethical framework. Pediatr Nephrol 2015;30:1761-9.

23. Teno JM, Fisher E, Hamel MB, et al. Decision-making and outcomes of prolonged ICU stays in seriously ill patients. J Am Geriatr Soc 2000;48(5 Suppl):S70-4.

24. Barlem EL, Ramos FR. Constructing a theoretical model of moral distress. Nurs Ethics 2015;22:608-15.

25. Papathanassoglou ED, Karanikola MN, Kalafati M. Professional autonomy, collaboration with physicians, and moral distress among European intensive care nurses. Am J Crit Care 2012;21: e41-52.

26. Sannino P, Giannì ML, Re LG, et al. Moral distress in the neonatal intensive care unit: an Italian study. J Perinatol 2015;35:214-17.

27. Gordon J. Moral distress caused by an uncertain prognosis: when the surrogate and the physician bring different priorities to the discussion. Am J Bioeth 2014;14:55-6.

28. Piers RD, Azoulay E, Ricou B, et al. Inappropriate care in European ICUs: confronting views from nurses and junior and senior physicians. Chest 2014;146:267-75.

29. Mishra V, Lindberg H, Seem E, et al. A comparison of hospital costs with reimbursement received for patients undergoing the Norwood procedure for hypoplasia of the left heart. Cardiol Young 2005;15:493-7. 